\title{
PERCEPTION OF IMPERFECT MOVIE VIEWERS ON WOMAN'S BODY IMAGE: SOCIAL AND ISLAMIC PRESPECTIVES
}

\author{
Rudi Pranata \\ SMA N 2 Lintau Buo, \\ Sumatera Barat, Indonesia \\ E-mail: rudipranata02@gmail.com \\ *Corresponding Author:

\section{Refika Mastanora} \\ Institut Agama Islam Negeri Batusangkar, \\ Sumatera Barat, Indonesia \\ E-mail: \\ refikamastanora@iainbatusangkar.ac.id
}

\section{Fufusia Syafira}

Sumatera Barat, Indonesia

E-mail: fufuziasyafira1999@gmail.com

\begin{abstract}
The purposes of this research are to describe the movie viewer's perception in interpreting and evaluating the communication behavior between characters, women's body image, and how Islam views physical changing intentionally by human in the Imperfect film. This type of research is qualitative with descriptive research methods. Data collection techniques used are observation, audience interviews, and documents. The results indicate the Imperfect film is a film that brings a very positive aura to the audience, of course, because this film teaches the audience to no longer look at and see someone based on their perfect physical appearance; slim and charming. In the perspective of Islam, it is obviously explained in QS. At Tiin: 4. It is stated that "God has created humans in the best possible form". In the scene, Rara as the main character successfully had an ideal posture. She preferred having an extreme diet for one month rather than doing plastic surgery. At the end of the film, the social message conveyed to the audience is to change the sense of Insecure to be more grateful because we were created with various strengths and weaknesses.
\end{abstract}

Abstrak: Tujuan dilakukan penelitian ini adalah untuk mendeskripsikan mengenai persepsi penonton dalam menafsirkan dan mengevaluasi perilaku komunikasi artis dalam film Imperfect dan mendeskripsikan mengenai persepsi penonton tentang body image perempuan dan bagaimana agama islam memandang jika terjadi perubahan bentuk fisik yang di sengaja oleh manusia. Jenis penelitian ini adalah kualitatif dengan metode penelitian deskriptif. Teknik pengumpulan data yang digunakan yaitu dengan cara observasi, wawancara penonton, dan dokumentasi. Hasil penelitian ini menunjukkan bahwa film Imperfect merupakan film yang membawa kepada aura yang sangat positif tentunya bagi penonton, karena film ini 
AGENDA : Analisis Gender dan Anak,Vol. 3 (2), 2021, (Desember)

ISSN Print: $\underline{2615-1502}$

ISSN Online: $\underline{2723-3278}$

Tersedia online di

http://ecampus.iainbatusangkar.ac.id/ojs/index.php/agenda

mengajarkan kepada penonton film Imperfect untuk tidak lagi memandang dan melihat seseorang berdasarkan bentuk fisiknya saja yang terlihat sempurna, apalagi perempuan selalu dituntut untuk berpenampilan langsing dan menawan, dalam perspektif Agama Islam QS.At Tiin:4 telah dijelaskan bahwasanya "Allah telah menciptakan manusia dalam bentuk sebaik-baiknya", dalam adegan tersebut Rara terlihat cantik setelah diet ekstreme selama 1 bulan, dia sebagai tokoh utama menampilkan berbagai ragam wanita dengan senyum bahagia tanpa harus mengambil jalan pintas yakni dengan cara operasi plastik. Diakhir film, pesan social yang disampaikan kepada para penonton yakni mengubah rasa Insecure menjadi lebih bersyukur karena kita diciptakan dengan berbagai kekurangan dan kelebihan masing-masing.

Kata Kunci: Persepsi, Body Image, sosial 
PENDAHULUAN:

Sebagai manusia tentunya dalam kehidupan sehari-hari, kita tak akan pernah terlepas dari kegiatan komunikasi bahkan hampir seluruh waktu kita habiskan untuk komunikasi dan berinteraksi dengan orang lain. sebagai makhluk sosial akan selalu haus akan informasi dan kebutuhan sosial lainnya sehingga manusia akan selalu terikat dengan manusia lainnya.

Menurut Liliweri, (2015) sebuah proses komunikasi digambarkan dari sebuah tangisan pertama ketika kita dilahirkan maka kelangsungan hidup kita sangat tergantung kemampuan kita belajar untuk mendengar dan menaggapi pesan dari orang lain. ketika salah satu pihak memberikan lalu merumuskan sebuah ide (encode) yang digunakan sebagai pesan, lalu mengirimkanya melalui beberapa saluran ke pihak lain yang disebut dengan penerima.

Setiap pesan yang diterima merupakan suatu umpan balik yang tentu saja terdapat proses dalam lingkungan yang ketika pesan itu dikirim dan dipertukan Misalnya adanya gangguan dari sebuah media yang dapat menimbulkan sebuah persepsi dari khalayak.

yang berupa pikiran, suasana batin, emosi, kecewaan, ketakutan dalam lingkungan nonfisik saat berinteraksi dan berkomunikasi. dengan adanya sebuah media sangat berpengaruh penuh terhadap perubahan yang dirasakan penerima sehingga dengan adanya media bermanfaat dan berpengaruh bagi kalayak dalam meningkatkan rasa percaya diri.
Berbagai banyak cara yang bisa dilakun untuk meningkatkan rasa percaya diri yaitu dengan melakukan sebuah perubahan. baik dari perubahan penampilan, gaya hidup, bentuk wajah, bentuk tubuh dan lain-lainnya yang bersifat perubahan. dengan adanya media seperti film dan tv banyak kalayak yang terinspirasi dan mengidolakan Artis Lokal maupun luar Negeri seperti Artis Korea yang mempunyai wajah dab bentuk tubuh yang menarik sehingga banyak kalayak terpengaruh dan menginginkan memiliki bentuk wajah dan tubuh seperti idolanya.

Salah satunya dengan melakukan operasi plastik untuk merubah tubuh fisik, baik itu dari wajah dan tubuh agar terlihat lebih ganteng dan cantik. Di Negara Indonesia sendiri operasi plastik banyak juga dilakukan oleh kalangan pablik figur seperti; pemain film, penyanyi dangdut bahkan orang biasa yang ingin melakukan operasi plastik untuk merubah bentuk fisiknya karna terinspirasi dari sang idola yang memiliki bentuk wajah dan fisik yang sempurna.

Pengaruh sebuah media seperti iklan, sinetron dan film secara tidak sadar melakukan penyeragaman budaya apa yang di sebut "menarik" secara fisik sehingga diferivikasi budaya mengenal apa yang menarik menjadi cenderung seragam. Sekarang ini akibat keinginan yang berlebihan memiliki bentuk tubuh "ideal" yaitu langsing dan cantik serta propesional banyak dari wanita yang terobsesi menjadi kurus hingga menyebabkan mereka mengidapkan kelaian psikologis anoreksia. Anareksia adalah ganguan 
makan disebabkan mereka yang terobsesi terhadap berat badan dan makan yang mereka makan, sehingga mencoba mempertahankan berat badan jauh dibawah normal dengan cara mengurangi makan yang berlebihan. (Priandono, 2016).

Dari dampak negatif munculnya sebuah media ternyata film lebih memiliki kelebihan khusus dari media lainnya. karena film dapat sangat berpengaruh dalam masyarakat karena masyarakat meyakini pesan yang disampaikan dalam sebuah film merupakan fenomena dan kejadian-kejadian yang benar-benar terjadi dalam kehidupan nyata.

Salah satunya film yang berjudul "Imperfect; karier, cinta dan Timbangan" film terlaris pada akhir 2019 lalu yang mana film ini mengangkat dari sebuah kisah nyata sang penulis buku best Seller terbaik Imperfect yang mengalami bodyshaming karena dia merupakan istri dari publik figur yang selalu dituntun untuk berpenampilan perfect sehingga dia banyak mendapatkan teguran dari khalayak. Oleh karena itu sang suami Ernest Perkasa menjadikan film sebagai media untuk menyampaikan informasi kepada khalayak bahwa penampilan fisik bukan berarti suatu permasalahan karena tidak ada manusia yang sempurna jadi mengajarkan kepada penonton film imperfect mengubah sudut pandang mereka tentang cantik tidak di ukur dari bentuk fisik maupun berat badan. Film ini juga banyak mendapatkan dukungan dan sebuah tangapan yang positif dari khalayak mengenai cerita disampaikan oleh istri Arnest tersebut.

Terbukti dalam 26 hari ditanyangkan serentak di bioskop-bioskop seluruh indonesia, film ini dapat menyingkirkan film yang terlaris urutan nomor ke 2 setelah film dilan yang pernah buming pada masanya (Sinopsis Imperfect: karier, cinta dan timbanganCCN. Indonesia. Com. Diakses 18 desember 2019).

film Imperfect memang membuat penonton merasakan secara langsung meski hanya menonton sebuah film. seperti yang telah kita ketahui selama ini bahwa fenomena mengenai penilaian bentuk fisik merupakan sesuatu yang sangat lumroh yang benar-benar ada dalam masyarakat. yang berdampak kepada seseorang tidak percaya diri dalam lingkungan sosial maupun dalam lingkungan internal baik itu dalam keluarga maupun sanak saudara,dan lingkungan internal dunia luar seperti; pekerjaan, lingkungan tempat tinggal dan lain-lain. jika ditinjau dari psikologi dan agama orang yang memiliki persepsi mengenai body image selalu mengakibatkan kepada tidak percaya diri (insecurity) baik kepada diri sendiri maupun orang lain, berdampak kepada mental dan jiwa yang merasa tergangguakibat rasa tidak percaya diri dengan bentuk fisik, penampilan yang

Asumsi ini mendorong peneliti untuk bagaimana memahami persepsi body image yang ditinjau dari dalam segi sosial, dan agama Islam dengan peneliti kaitkan dengan teori dari Liliweri mengenai bagaimana individu memproses sebuah 
informasi impression formation theori, sehingga kita bisa mengetahui bagaiamana membentuk kesan tentang orang lain berdasarkan kualitas fisik dan perilaku orang tersebut, sumber informasinya berasal dari cerita mereka tentang diri mereka. jadi peneliti ingin lebih memfokuskan penelitian pada film imperfect dengan judul: "Persepsi Body Image Perempuan Dalam Film Imperfectdi Tinjau dari Perspektif sosial, dan Agama Islam”

\section{METODE:}

Jenis penelitian ini termasuk penelitian lapangan (field research) yaitu suatu penelitian yang dilakukan secara sistematis dengan mengangkat data yang ada dilapangan. Metode yang digunakan pada penelitian ini adalah menggunakan metode penelitian kualitatif deskriptif. metode kualitatif adalah menelaah berbagai masalah penelitian dari fenomena yang ada melalui pengamatan perilaku, persepsi, tindakan secara holistik dengan cara deskriptif dalam bentuk katakata tertulis atau lisan dari orang-orang dan perilaku yang dapat di amati dengan memanfaatkan data secara alamiah. Menurut Moleong (2006: 6). Teknik pengumpulan dengan tringulasi (gabungan), analisis data bersifat induktif/kaulitatif dan hasil penelitian kualitatif lebih menekankan makna dari pada generalisasi.

Jadi melalui penelitian kualitatif ini penulis akan mengkaji berbagai aspek terkait dengan film Imperfect berdasarkan pandangan agama dan sosial.
Penulis melakukan penelitian pada bulan mei hingga bulan agustus 2021 .

Peneltian kualitatif, yang menjadi instrument kunci penelelitian adalah peneliti sendiri. Peneliti mengungkap data secara lebih mendalam menggunakan pedoman wawancara dan panduan studi dokumen, camera handphone untuk merekam hasil wawancara.

Sumber data primer dari penelitian ini Penonton film Imperfect sendiri yang pernah menonton film tersebut dan bisa menafsiran dan mengevaluasi dari film Imperfect sesuai dengan Teori Liliweri.

Teknik pengumpulan data yang digunakan dalam penelitian ini adalah dengan meggunakan observasi, wawancara dan dokumentasi.

Observasi adalah pengamatan yang dilakukan oleh panca indera manusia. Observasi sebagai teknik pengumpulan data biasanya dibagi menjadi dua partisipatoris dan non partisipatoris. Observasi dilakukan dengan cara mencatat dan menangapi pertanyaan dari informan film imperfect

Teknik wawancara adalah proses pengumpulan data yang akan menghasilkan data yang akurat dan terperinci. Wawancara peneliti lakukan kepada penonton film imperfect yang mana difilm imperfect menceritakn berbagi persepsi ditinjau dari sosial, psikologi dan agama, maka peneliti ingin mewawancarai sesuai dengan persepsi dari masing-masing penonton.

Metode dokumentasi merupakan data yang diperoleh berupa gambar, buku, 
arsip, gambar yang berkaitan dengan penelitian. Dokumentasi ini dapat membantu dan mendukung data dan memperkuat hasil penelitian. Seluruh data yang dikumpulkan dengan mempelajari data-data tentang film Imperfect berupa $\mathrm{dvd}$ film/video, screenshoot foto dari data pendukung jawaban penonton dengan memanfaatkan google from, situs internet, buku, media elektronik, new media, dan dll.

Teknik Analisis Data dalam penelitian ini adalah mencari dan menyusun secara sistematis data yang di peroleh dari hasil wawancara, catatan lapangan, dan dokumentasi, dengan cara mengorganisasikan data dalam kategori, menjabarkan ke dalam unit-unit, melakukan sintesa, menyusun kedalam pola, memilih mana yang penting dan yang akan di pelajari, dan membuat kesimpulan sehingga mudah dipahami oleh diri sendiri maupun orang lain. (Sugiyono, 2016:244).

Penyajian hasil penelitian ini dipaparkan deskriptif berdasarkan temuan dilapangan dengan Bahasa khas dan pandangan emik informan agar mudah dipahami oleh pembaca. Melakukan interprestasi data yaitu menginterprestasikan apa yang telah diinterprestasi oleh informan terhadap masalah yang diteliti.

Pada tahap ini penelti melakukan interprestasi data sesuai dengan konteks permasalahan dari tujuan peneliti. Dari interprestasi yang dilakukan akan diperoleh kesimpulan dalam jawaban masalah penelitian.
Teknik tringulasi yang penulis gunakan adalah teknik tringulasi sumber, teknik dan waktu.

\section{HASIL DAN PEMBAHASAN:}

Berdasarkan hasil penelitian terkait film. Penulis menguraikannya sebagai perilaku komunikasi artis dalam Film Imperfect sebagai berikut:

Temuan pertama terkait dengan persepsi penonton dalam menafsirkan dan mengevaluasi Perilaku komunikasi artis film Imperfect adalah sebuah karya film menceritakan tentang rasa Insecure seseorang terhadap body image yang dimiliki, sebagian besar perempuan ada yang merasa tidak percaya diri dengan berat badan, gigi, rambut dan lain-lainnya.

Dalam temuan ini penonton juga berpendapat di kehidupan sosial seseorang dituntut berpenampilan sempurna dan akan selalu dibanding-bandingkan dengan bentuk fisik orang lain, namun yang sering menjadi korban bullying fisik adalah perempuan, sehingga berdampak kepada kehidupan nya dalam dunia kerja maupun sosial akan selalu tidak percaya diri karena merasa insecure dan tidak pantas berada ditengah-tengah masyarakat.

Temuan kedua mengenai cara penonton menganalisir dan mengevaluasi perilaku artis dalam film Imperfect melihat berdasarkan sifat dan tingkah laku seseorang apakah dia baik apa tidak, lalu mengamati seseorang dari suatu kesamaan dalam film dengan dirinya dalam perilaku artis memncerminkan dirinya sendiri dalam kehidupan sehari-hari seperti Endah yang mempunyai masalah yang sama 
dengan Informan lalu mempunyai segi kesamaan dengan sang artis melihat dari tutur bahasanya, nada berbicarnya tinggi atau rendah seperti perilaku dika yang sering emosional jika mengahadapi sutu permasalahan seperti menolong Endah yang di ganggu preman di adegan itu Dika memukul preman yang sering menganggu Endah sehingga Camera yang digunakan untuk Fotografer Rusak, dengan cara mengamati dengan baik setiap konsep yang diperankan para artis atau tokoh sehingga mengetahui bagaimana perilaku artis tersebut.

Temuan ketiga terkait dengan Imperfect sudah sesuai dengan ajaran agama Islam atau tidak jawabanya ia karena mengajarkan kita untuk lebih bersyukur dengan apa yang kita miliki tidak ada yang sempurna, karna kesempurnaa datangnya dari sang pencipta, lebih mengajarkan kita menerima. dalam agama Islam barang siapa yang melakukan kebaikan dan orang itu mengikutinya berarti dia mendapatkan pahala dari orang yang mengikutinya, seperti sosok Rara yang mempunyai hati yang baik mengajarkan anak jalanan tentang pendidikan dan tidak lupa mengajarka tentang tidak boleh melakukan body shaming. antagonis Marsya merupakan perbuatan yang paling tidak di sukai oleh Allah Kita sebagai umat Muslim dilarang mempunyai sifat tersebut, sosok Rara menjelaskan bahwa ketika dia sudah mendapatkan apa yang dia inginkan dia melupakan semua yg ada dengan dirinya lupa bersyukur. Adanya rasa toleransi umat beragama dalam film
Imperfect perbedaan tidak menghalangi untuk berteman dan menghargai sesama umat beragama

Temuan Keempat terkait dengan komunikasi interpersonal para artis dalam film Imperfect adalah bagaimana dia ingin mengapai sesuatu yang dia inginkan seperti rara yang bertekat menurunkan berat badan dengan tekat yang bulat dia bisa mencapai berat badan yang dia inginkan tapi ketika dia sudah berhasil dia melupakan semua yang pernah dia lalui dan lupa bersyukur, sosok masha yg ambisius ingin menjatuhkan Rara dia ingin membuat Rara sosok yang buruk, dan dia orang yang angkuh dan iri merasa paling cantik dari yang lain dan merasa bahwa Rara bukan lah tandinganya, sosok dika merupakan sosok laki-laki idaman para wanita Karena menerima Rara apa adanya dan dia sosok orang yang menunjung tinggi kehormatan dan menolong Endah yang sering digoda pereman komplek, sosok ibu Rara yang selalu memaksakan kehendak

Dari keempat pertemuan diatas dan setelah peneliti menonton film Imperfect dapat peneliti simpulkan bahwasanya film ini merupakan film yang sangat membawa aura yang positif dapat menyadarkan seseorang yang mengalami body image lebih percaya diri lagi dan bersyukur bahwasanya masih ada orang memiliki pengalaman yang sama dengan dirinya seperti Rara dia bias membuktikan bahwa Bersyukur bisa membahagiakan diri sendiri dan memberikan pelajaran kepada kita akan selalu berbuat baik dari sosok Rara mengajarkan kita menjadi diri sendiri 
karena aka nada sosok seperti Dika yang akan menerima kekurang asalkan bersyukur, prilaku para artis mencerminkan sebuah persespi dalam kehidupan masyarakat yang menuntut untuk menjadi sempurna padahal kesempurnaan hanya lah milik Allah (Maha Pencipta), selalu lah berbuat baik dan jauhi perbuatan buruk seperti peran masha dalam film Imperfect. Pelajaran yang dapat kita petik jangan menilai seseorang dari berat badan, bentuk fisik dan penampilan karna belum tentu apa yang dilihat seperti yang tampak.

\section{KESIMPULAN}

Berdasarkan analisis data yang peneliti lakukan tentang Film Imperfect ditinjau dari persektif sosial, dan agama Islam dapat memperoleh kesimpulan sebagai berikut;

a) Persepsi penonton dalam menafsirkan dan mengevaluasi prilaku komunikasi artis dalam film Imperfect adalah terlalu memaksakan kehendak akan suatu penampilan yang harus dituntut memiliki berat badan ideal, selalu dibandingkan dengan orang yang memiliki tubuh langsing, dalam agama Islam tidak boleh memaksakan sesuatu jika tidak bisa tercapai karna suatu yang dipaksakan merupakan suatu yang tidak baik misalnya merubah bentuk atau ciptaan dari Allah kecuali memperbaiki kekurangan maka dibolehkan dengan syarat tidak merubah jauh dari semestinya apabila tujuan untuk kecantikan maka diharamkan lebih baik bersyukur dengan apa yang dimiliki tiada yang sempurna kecuali sang pencipta dari Alam semesta. Mengajarkan kita tentang tidak boleh menilai seseorang berdasarkan penampilan karna yang dilihat belum tentu sama. Misalnya sosok Rara meski dia selalu dipandang sebelah mata ternyata dia bisa membuktikan bahwa dia bisa menjadi meneger sekaligus wanita cantik yang mempunyai otak pintar.

b) Persepsi penonton dalam memandingkan dirinya dan orang lain setelah menonton film Imperfect setelah menonton film Imperfect membuat penonton lebih bersyukur dengan apa yang dimiliki yaitu mengubah kata insecure menjadi lebih bersyukur dan tidak boleh memandingkan diri sendiri dengan orang lain karena kita memiliki potensi dan kemampuan yang berbeda-beda dari sosok Rara kita bisa belajar bahwa yang cantik belum tentu menarik karena yang menarik adalah seseorang bisa bersyukur dengan apa yang dia miliki jangan pernah pantang menyerah dalam mengapai impian jangan pernah melakukan perbuatan buruk selalulah melakukan kebaikan seperti Rara

c) Motivasi dalam film ini adalah mengubah rasa insecure menjadi bersyukur karena kodratnya semua wanita itu cantik, namun isi hatinya akan memancarkan sendiri kecantikan dari dalam masing-masing perempuan. 


\section{DAFTAR PUSTAKA}

Listyana, R. dan Hartono, Y. 2010. Persepsi dan Sikap Mahasiswa Terhadap Penanggalan Magetan. 5(1): 121- Jawa dalam Penentuan Waktu Penentuan Waktu Pernikaha: StudiKasus Desa Jonggrang Kecamatan Barat Kabupaten 122.Liliweri, A. 2015. Komunikasi Antar-Personal. Edisi Pertama. Cetakan Pertama.Kencana Prenada. Jakarta.

Maulana, H. 2013. Psikologi Komunikasi. Edisi Pertama. Cetakan pertama.Gumelar Gumgum. Jakarta.

Moleong, Lexi, J. 2006. Meteodologi Penelitian Kuantitatif/ Lexi J. Moleong. Edisi Revisi. PT Remaja Rosdakarya. Bandung.

Nasrullah, R. 2014. Media Siber (CYBERMEDIA). Edisi pertama. Cetakan Kedua.Kharisma Putra Utama. Jakarta.

Priandono, T., E. 2016. Komunikasi Keberagaman. Edisi Pertama. Cetakan Pertama.PT Remaja Rosdakarya. Bandung.

River, W.L., Jensen, J.W., dan Peterson., 2003. Media Massa \& Masyarakat Modren. Edisi Ketiga. Cetakan Kedua. Pranda Media. Jakarta.

Sobur, A. 2013. Filsafat Komunikasi: Tradisi dan Metode Fenomenologi. Edisi Kedua. Cetakan Kelima. PT Remaja. Bandung.

Sobur, A. 2016. Semiotika Komunikasi. Edisi ketiga. Cetakan Keenam. PT Remaja Rosdakarya. Bandung.
Sondak, S. H. (2019). Faktor-Faktor Loyalitas Pegawai Di Dinas Pendidikan Daerah Provinsi Sulawesi Utara. Faktor-faktor Loyalitas Pegawai Di Dinas Pendidikan Daerah Provinsi Sulawesi Utara, 676.

Sugiyono, 2013. Meteodologi Penelitian Kuantitatif, Kuantitatif dan R\&D. Alfabeta. Bandung.

CCN.Indonesia.Com. ( 18 desember 2019). Sinopsis Imperfect: Karir, Cinta, dan Timbangan. CCN Indonesia. 18 desember 2019. Jakarta: CCN. Indonesia. Com

Khaeriyah, S. Mamesah, M. Dan Tjalla, A. 2017. Persepsi Terhadap Body Image Antar Siswayang Mengunakan Jilbab dengan Siswi Tidak Mengunakan Jilbab:Studi Kasus Komplatif di Smk Tirta Sari Jakarta Timur. Jurnal Bimbingan dan Konseling (150). 